\title{
Field Efficacy of Insecticides on Population Dynamics of Grain Sucking Bugs of Upland Rice, Oryza Sativa
}

\author{
Onunkun, $\mathrm{O}$ \\ Agricultural Science Department, Adeyemi College of Education, Ondo, Nigeria
}

\begin{abstract}
Effectiveness of three insecticides, monocrotophos(Azodrin 60EC), Cypermethrin(Cymbush 10EC) and Carbaryl(Vetox 85WP) at specified spray schedule, were evaluated in comparison to untreated control treatment for the management of common upland rice sucking bugs, Aspavia armigera and Stenocoris claviformis. . Cypermethrin at the rate of $15 \mathrm{~kg}$ a.i./ha was most effective at reducing the population of of the sucking bugs, 24 and $72 \mathrm{hrs}$ after application while carbaryl at 1.5kg a.i./ha was observed to be most effective in producing residual effect on the sucking bugs. Carbaryl at $1.5 \mathrm{~kg}$ a.i./ha provided better reduction in the population of rice bugs. The application of the selected insecticides did not result in increase in yield of upland rice. Application of insecticides to control sucking bugs in upland rice should strictly be based on damage threshold of the insect pest.
\end{abstract}

Keywords: Pyrethroids. rice bugs, threshold, residual.

\section{Introduction}

Rice is the most rapidly growing food commodity in sub-Saharan Africa because of changes in consumer preferences and urbanization. In 2009 the continent imported one-third of what is available in the world market costing an estimated US\$5 billion [1]. The average quantity of rice imported annually in west Africa increased from 0.4 million $t$ in 1964 to almost 1.8 million $t$ in 1984, growing to 2.5 million $t$ in 1995 . Senegal, Côte d'Ivoire, and Nigeria ranked among the top rice importers in the world [2]. Nigeria is the largest producer of rice in the West Africa sub-region. Today, rice is no longer a luxury food to millions of Nigerians but has become the cereal that constitutes a major source of calories for the rural and urban poor with demand growing at an annual rate of 5 per cent [3].

According to [4] biotic factors of insect pests and diseases as w ell as adverse weather conditions were the two major limiting factors responsible for low rice yields in Nigeria. G Pests cause considerable and unacceptable crop losses in the field and in storage [5]. Serious damage to the rice crop by a complex of insect pests results in significant yield losses which are typically in the range 10-30\% yields and, in some regions or years, may exceed 90\% [6]. Although data on yield losses caused by insects on upland rice are not readily available, between 25-30\% yield losses have been estimated in Nigeria. That of upland rice in Africa is in the range of $14.4 \%$ to $30 \%$ [7].

Several hemipterous bugs belonging to the families Alydidae and Pentatomidae that feed by sucking the sap of developing spikelets cause serious rice crop losses [8]. Among the 15 species of grain suckers known in West Africa, Aspavia armigera (F) (Pentatomidae) and Stenocoris claviformis Ahmad (Alydidae) are important. Damaged grains have diffuse brown spots at the point of feeding. Heavily damaged grains are either empty or only partially filled. The adult Aspavia is brown with a yellow colour spot at each corner of the triangular shield. Its prothoracic plate has a pointed projection at each side of the dorsal side. Stenocoris is similar in appearance to the Asian sucking bug, Leptocorisa sp. The Aspavia $s p$ is said to be the predominant species throughout the growth stages of rice in upland rice [9].

[10]. Indicated that previous attempts to increase rice production through the use of improved varieties and fertilizers alone, without proper regard for plant protection measures were unsuccessful because they resulted in severe losses from increased pest and disease damage. [11] noted that though Korea achieved self sufficiency in rice production in 1977 through the widespread planting of high yielding cultivars and application of fertilizers. This was short lived (two years after) by outbreak of sheath blight, blast and plant hopper insects which caused a 19\% decrease in production. In order to prevent future losses to insects and pests, the use of fungicides and insecticides were promoted beginning in 1980. [12] reports that approximately $75 \%$ of Korea's rice acres are treated with insecticides.

In a study on risk assessment of insecticides used in rice on miridbug, Cyrtorhinus lividipennis Reuter, the important predator of brown planthopper, Nilaparvata lugens (Stal.) endosulfan, chlorpyriphos, acephate and methyl parathion are regarded as safer to $C$. lividipennis based on selectivity ratio, hazard quotient and probit substitution method of risk aassessments[13]. The use of insecticides in rice, it appears, will continue, at least in the near future, notwithstanding increased interest in integrated pest management; furthermore, integrated pest management does not preclude pesticide usage [14]. 
In view of the reduction in yield caused by these insects, desirable insect pest management practices are seriously necessary and needed. Heong (1983) showed that the use of insecticides under various conditions in nearly all rice growing countries has resulted into a significant increase in rice yield. In this study attempts were made to study the efficacy of selected insecticides on the sucking bugs of upland rice.

\subsection{Location}

\section{Materials and Methods}

The field experiments were conducted in 2011 planting season at the Teaching and Research Farm, Adeyemi College of Education, Ondo (Latitude $07^{\circ} 05^{\prime} \mathrm{N}$, Longitude $04^{\circ} 50^{\prime} \mathrm{E}, 27.5 \mathrm{~m}$ ). The research area was a rain forest zone of Nigeria. During land preparation the field was cleared, ploughed, harrowed and an area of $441 \mathrm{~m}^{2}$ was marked out and divided into sixteen subplots. Each subplot measuring $4.5 \mathrm{~m} \times 4.5 \mathrm{~m}\left(20.25 \mathrm{~m}^{2}\right)$ was separated by a pathway of $1-\mathrm{m}$. The planting material, an early maturing upland rice variety, FARO 45 (ITA 257), was obtained from the International Institute of Tropical Agriculture (IITA), Ibadan, Oyo State, Nigeria. The seeds were planted at the rate of $60 \mathrm{~kg}$ per hectare and spacing of $25 \mathrm{~cm} \mathrm{x} 25 \mathrm{~cm}$ between and within the rows. A top dressing application of fertilizer was done with NPK $(15: 15: 15)$ at the rate of $60 \mathrm{~g} / \mathrm{ha}$ immediately after emergence- three weeks after planting (WAP) and during panicle initiation. Weeding of the plots was done by a hand hoe three times, every three weeks starting from 3WAP.

The experiment was a randomized complete block design with four treatments replicated five times. The treatments were made up of three insecticides, Monocrotophos (Azodrin), Cypermethrin (cymbush), carbaryl (Vetox 85) and a control. The insecticides were sprayed four times at 14- day intervals from 40 to 82 days after planting. The recommended rates of application are as follows: Monocrotophos, $700 \mathrm{~g}$ a.i./ha; carbaryl $1.5 \mathrm{~kg}$ a.i/ha; and Cypermethrin $150 \mathrm{~g}$ a.i./ha. The effectiveness of the various treatments was assessed by estimating the relative abundance of the pests in the treated and untreated plots, insect and grain yield

\subsection{Estimating the Population and Percentage Damage of Grain-Sucking bugs}

The rice bugs, Aspavia armigera and Stenocoris sp, were counted visually. Counting was done at flowering stage usually in the morning when their activities are reduced [15]. An area of $1-\mathrm{m}^{2}$ was chosen at four different sites in each plot and number of bugs recorded. Timing of sampling was before application 1, 7 and 14 days after application of the insecticide.

Damage due to the sucking bugs was estimated by randomly selecting one-tenth of the total heads from each plot at harvest. The samples were inspected for sterile seeds resulting from the feeding activities of sucking bugs. Threshing of the samples was done by hand. The total number of seeds and the damaged ones were recorded and the percentage loss estimated. The samples were subsequently added to the remaining heads and weighed[16]. The sucking bugs, Aspavia armigera and Stenocoris sp were counted once every week.

\subsection{Estimating the grain yield}

The upland rice variety, FARO 45 (ITA 257), is a short duration type ready for harvesting 100 to 108 days after planting. For yield estimates, rice plants in the middle rows were harvested while those on the borders were excluded. The harvested rice was dried for about three weeks and later threshed by hand. Seeds obtained from each plot were weighed on a balance and unhulled grain yield data were also analyzed.

\section{1}

\section{Results and Discussion}

\section{Percentage reduction in sucking bugs population}

The percentage reduction in population of rice sucking bugs, Aspavia armigera and Stenocoris spp sprayed with three different insecticides are as presented in Figures 1 and 2. All the insecticidal treatments produced a maximum reduction in the population of Aspavia armigera per plant compared to control which caused 3\% reduction at $24 \mathrm{hrs}$ after application (Figure 1). The reduction in population observed in untreated plots was probably due to insecticide drift. The population of Aspavia spp in the control plots was unchanged. However, three days (72 hrs) after application of treatments the population of Aspavia spp reduced by $75 \%$ with cypermethrin, $84 \%$ with monocrotophos and $86 \%$ with carbaryl compared to the value of $6.5 \%$ in control. During this period of observation, the reduction in population of the sucking bug was greatest for carbaryl. At $120 \mathrm{hrs}$ after application of treatments, while cypermethrin caused reduction of $58 \%$ in population of Aspavia armigera, there was no significant difference between reduction in population of the pest with monocrophos and carbaryl (46\% and 50\% respectively). Figure 2 shows the effect of the selected insecticides in reducing the population of rice sucking bug, Stenocoris spp. The effect of insecticides on this insect pest followed the observed trend in Aspavia armigera, except that the insecticides did not produce maximum reduction with monocrotophos and carbaryl $24 \mathrm{hrs}$ after application. There was no reduction in the untreated check 24,72 and 
$96 \mathrm{hrs}$ after application of insecticides. At $120 \mathrm{hrs}$ after spraying of insecticides, the population of the sucking bugs reduced by $6 \%$ in the control plots.

In this study, the major grain sucking bugs identified at Teaching and Research Farm, Adeyemi College of Education were A. armigera and S. claviformis. This confirmed the report of [9] who showed that the most important grain suckers in upland rice were A. armigera and $S$. claviformis. These observations confirmed the work of [17] who reported that currently rice growers use carbaryl, lambdacyhalothrin, zeta-cypermethrin, and methyl parathion for rice stink bug control. Research has found no resistance to these insecticides.

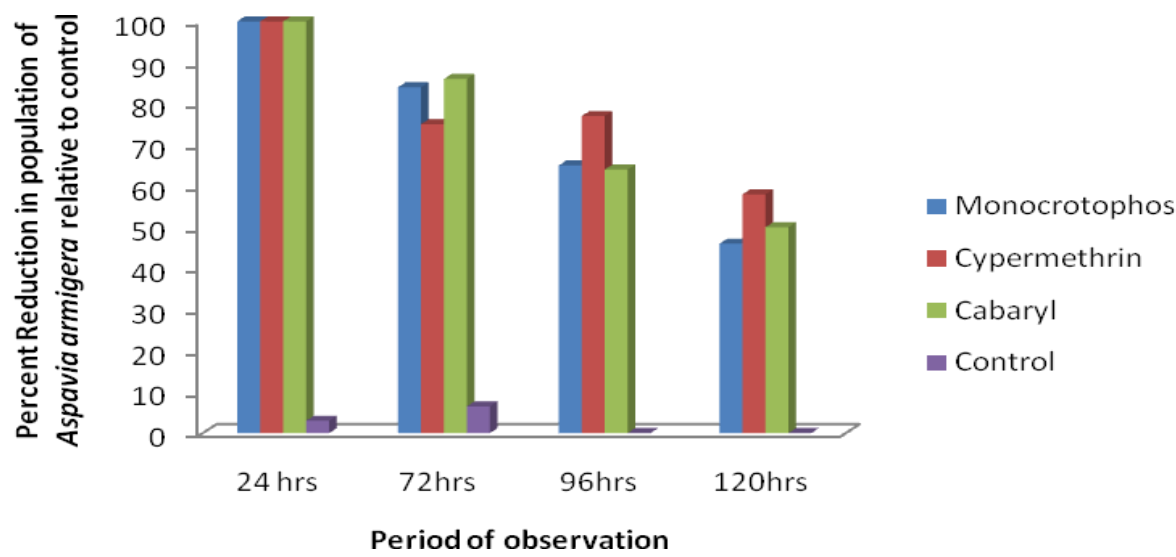

Figure 1: Percent reduction in population of Aspavia armigera relative to the untreated Control'

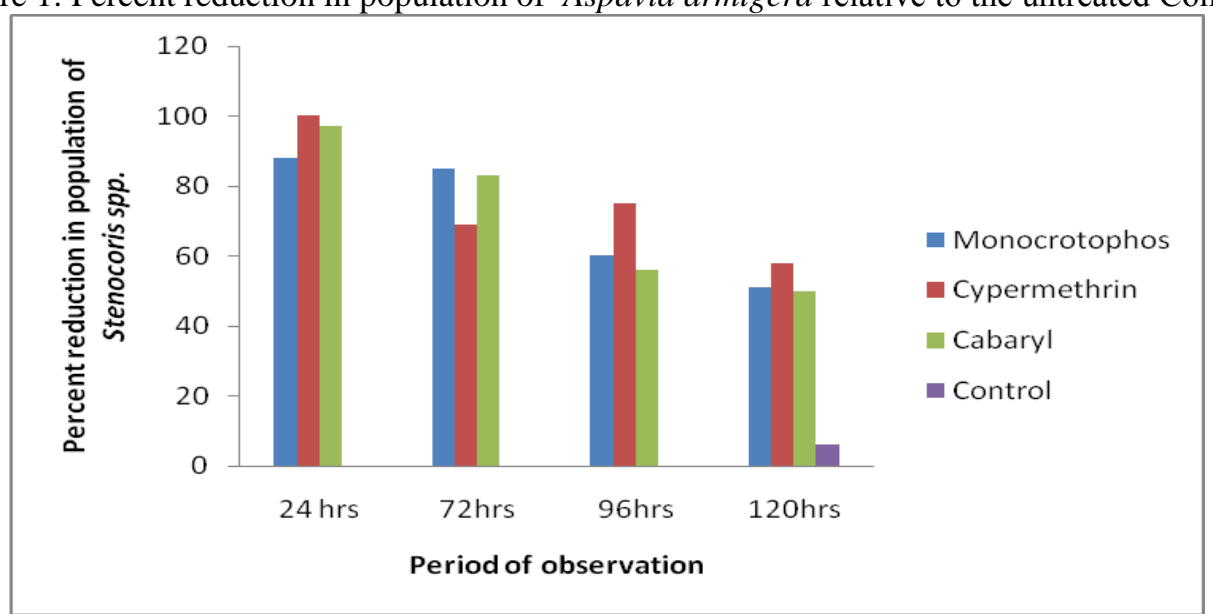

Figure 2: Percent reduction in population of Stenocoris spp relative to the untreated Control'.

Experiments have shown that the insecticide application can reduce stink bug populations by $95 \%$. Lorenz and Hardke in a related study reported that sevin (carbaryl) will have some initial kill with 3 to 5 days of residual activity, while synthetic pyrethroid insecticides will have good initial kill and 1 to 2 days of residual activity.

\subsection{The Effect of Insecticidal Treatment on Seed Production in rice}

Table 1.0: Mean damaged seeds by sucking bugs on upland rice sprayed with three synthetic insecticides.

\begin{tabular}{lllll}
\hline Treatments & $\begin{array}{l}\text { Mean } \\
\text { number } \\
\text { of seeds }\end{array}$ & $\begin{array}{l}\text { Mean number of } \\
\text { damaged } \\
\text { panicles }\end{array}$ & $\begin{array}{l}\text { Mean } \\
\text { damaged } \\
(\%)\end{array}$ & $\begin{array}{c}\text { Yield } \\
\text { (tons/ha) }\end{array}$ \\
\hline Cypermethrin 10EC & 26.72 & $16.25^{\mathrm{a}}$ & $0.5^{\mathrm{a}}$ & $2.05^{\mathrm{a}}$ \\
Monocrotophos 60EC & 40.01 & $34.75^{\mathrm{a}}$ & $0.93^{\mathrm{a}}$ & $2.10^{\mathrm{a}}$ \\
Carbaryl 85WP & 40.24 & $25.75^{\mathrm{a}}$ & $0.6^{\mathrm{a}}$ & $2.50^{\mathrm{a}}$ \\
Control & 37.39 & $55.3^{\mathrm{a}}$ & $1.5^{\mathrm{b}}$ & $2.00^{\mathrm{a}}$
\end{tabular}

C.V $(\%)$

Means followed by the same letter(s) in a column are not significantly different from each other at $\mathrm{p}<0.05$ according to Duncan Multiple Range Test(DMRT) 
The mean number of damaged seeds by sucking bugs and yield of rice when sprayed with three synthetic Insecticides are presented in Table 1. There was no significant difference among the treatments on in mean number of damaged seeds per 10 panicles. However, there was a significant difference among the treatments in mean percentage damage of seeds by sucking bugs $(\mathrm{p}<0.05)$.

Mean percentage damage of seeds was highest in untreated plots (1.5\%) and lowest in cypermethrin treated plots $(0.5 \%)$. Table 1 also revealed that the seed yield of rice did not differ significantly by the different treatments. Though the highest yield per ton was recorded in carbaryl treated plots (2.00ton/ha), this was not statistically different from that of monocrotophos 60EC (2.10ton/ha), cypermethrin (2.05ton/ha) and untreated plot (2.00ton/ha). This could be as a result of the low population density of sucking bugs observed in all the treatments. Sucking bugs have been reported by several authors to be more dependent on resources provided by weeds than the other pests. [18] in their work on effects of five weed management regimes on abundance of weeds, insect pests, generalist predators and on pest damage and rice yield reported highly significant negative correlation between weed biomass and grain yield across all treatments. It was observed in the study that only two pest insect groups, Nephotettix spp. (Cicadellidae) and seed sucking Heteroptera, were consistently more abundant in unweeded plots and had a consistent significant positive

\section{Conclusion}

This study showed that the selected insecticides are very effective in controlling insect pests of rice. The experiment also indicated that carbaryl (vetox 85WP) performed very well in reducing the population of rice sucking bugs with 3-5 days of residual effect. Though there was no significant difference in grain yield among the treatments. The generally low population of grain sucking bugs in this study was presumed to have accounted for this very close yield obtained among treated and untreated rice plants. [19] also showed that the incidence of insect pests on rice is generally low and the yield in untreated plots (4.6 tons/ha) was very close to average yield in treated plots of 5.00 tons /ha. This study has indicated the effectiveness of the selected insecticides in reducing the population density of rice sucking bugs which damage rice grains and reduce yield significantly in situations where the population is in abundance. Further research is necessary to determine the economic threshold for these pests in order to minimize cost of production.

\section{References}

[1] Africa Rice Center (Africa Rice) 2011. Boosting Africa's Rice Sector: A research for development strategy 2011-2020. CotonouBenin: ii + 77pp.

[2]. WARDA, 2000. Annual Report

[3]. Oikeh, S.O., F.E. Nwilene, T.A. Agunbiade, O. Oladimeji, O. Ajayi, S. Mande, H. Tsunematsu, H. Samejima. 2008. Growing upland rice: a production handbook. Africa Rice Center, Benin. 40 pp.

[4]. Pathak M.D, Khan Z.R. 1994. Insect pests of rice. Manila (Philippines): International Rice Research Institute. 89p.

[5]. Nwilene, F. E.; Togola, A; Oyetunji, O. E; Onasanya, A. ; Akinwale, G. ; Ogah, E. ; Abo, E. ; Ukwungwu, M.; Youdeowei A. and N. Woin (2011). Is Pesticide Use Sustainable in LowlandRice Intensification in West Africa?, Pesticides in the Modern World - Risks and Benefits, Dr. Margarita Stoytcheva (Ed.), ISBN: 978-953-307-458-0

[6]. Nguu V. N. 2008. Sustainable intensification of rice production for food security in the near future - A summary report by the secretary, International Rice Commission. Pp 1-14.

[7]. Cramer, H.H 1977. Plant Prtotection and World Crop Production. Pflschultz - Nach Bayer 20: 1-524

[8]. M.D Pathak and Z.R Khan, 1994. Insect pests of rice. International Rice Research Institute. Pp 89.

[9]. Alam., M.S., and I.A.Lowe (1989). Incidence of two grain suckers in irrigated and upland rice, in: International Rice Research Newsletter (IRRN) 14:1

[10]. FAO, (1966). Rice-grain of life. Food and Agriculture Organisation of the United Nation, Rome, Italy. Pp. 1 -3; 38

[11] Chung, H-S. 1980. Plant protection in the Republic of Korea. In: Plant Protection in Three Asian Countries. ASPAC Extension Bulletin No. 145.

[12] Shepard, B.M., Z.R. Khan, M.D. Pathak and E.A. Heinrichs. 1991. Management of insect pests $\quad$ of $\quad$ ince Asia. CRC Handbook of Pest Management in Agriculture, 2nd Edition. Vol III.

[13] Preetha G, Stanley J, Suresh S, and R. Samiyappan.2010. Risk assessment of insecticides used in rice on miridbug, Cyrtorhinus lividipennis Reuter, the important predator of brown planthopper,Nilaparvata lugens (Stal.). Chemosphere. 80(5):498-503.

[14] Magallona, E. D.1989. Effects of Insecticides in Rice Ecosystems in Southeast Asia. Ecotoxicology and Climate. Eds. P. Bourdeau, J. A. Haines, W. Klein and C. R. Krishna Murti @ 1989 SCOPE. Published by John Wiley \& Sons Ltd.

[15] Heinrichs E.A; S. Cheillah; S.L. Valencia; M.B. Arceo; L.T.Fabellar; G.B. Aquino; and S. Pickin. 1981. Manual for testing insecticides on rice. IRRI.

[16] (Swanson et $\underline{\text { al, }}$ 1962).

[17] Castro, Boris A., "Efficacy of Insecticides at Selected Rates on Management of Rice Stink Bugs in Rice," Arthropod Management Tests, 2004.

[18] J.V.K. Afun, D.E. Johnson and A. Russell-Smith (1999). Weeds and natural enemy regulation of insect pests in upland rice; a case study from West Africa. Bulletin of Entomological Research.

[19] Rao, P. U., M.V.S. Sastry, J.R.K. Rao, G.S.V. Prasad, and M. B. Kalode. 1995. Breeding varieties resistant to major insect pests in rice, pp. 223-227. In Genetic research and education: current research and the next fifty years. Indian Society of Genetics and Plant Breeding, New Delhi, India. 